\title{
Early outcomes with a hybrid technique for repair of a non-A non-B aortic dissection
}

\author{
Weitie Wang, MD, Hulin Piao, MD, PhD, Yong Wang, MD, Bo Li, MD, PhD, Zhicheng Zhu, MD, PhD, \\ Tiance Wang, MD, and Kexiang Liu, MD, PhD
}

\section{ABSTRACT}

Objective: This study reports the early outcomes of patients with acute non-A non$B$ aortic dissection that involved the aortic arch but not the ascending aorta.

Methods: From January 2013 to December 2018, 825 patients presented with aortic dissection. Of these, 28 patients with non-A non-B dissection (classified as dissection extending into the aortic arch with entry between the left common carotid artery and the left subclavian arteries) underwent a novel hybrid surgery. Self modified stent-grafts (Micropart Corp, Shanghai, China) were implanted via median sternotomy. Clinical presentation, postoperative data, and early outcomes were recorded.

Results: All patients underwent an emergency operation. There were no in-hospital mortalities, reexplorations for hemorrhage, reports of paraplegia, cerebral infarctions, endoleaks, or left subclavian artery occlusions. No blood products were required during or after the operations. During the early follow-up at $39.12 \pm 15.04$ months (6.0-74.0 months), 1 patient was lost to follow-up, and 1 patient died suddenly. Computed tomography angiography showed false lumen patency persisted in the aortic arch and descending aorta without any symptoms. The 6-month computed tomography angiography showed significantly smaller distal aortic arch diameters $(31.94 \pm 6.95 \mathrm{~mm})$ and descending aorta diameters $(34.84 \pm 4.15 \mathrm{~mm})$ than measured preoperatively $(36.76 \pm 4.15 \mathrm{~mm}$ and $37.31 \pm 4.7 \mathrm{~mm}$, respectively). No paraplegia, cerebral infarction, upper limb ischemia, or left subclavian artery ischemia events were reported.

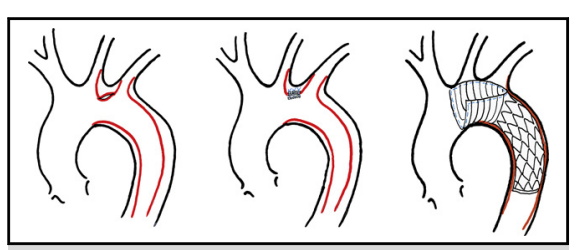

Schematic diagram of modified SG in non-A non-B AD.

\section{CENTRAL MESSAGE}

The inclusion aortic arch tech-

nique is easily performed and requires no blood products with satisfactory early outcomes.

\section{PERSPECTIVE}

There is no consensus regarding the best treatment for acute non-A non-B AD. The novel hybrid technique is an effective treatment that is safe to perform and requires no blood products during and after the operation.

See Commentaries on pages 1775 and 1776.

Conclusions: Our inclusion aortic arch technique is a safe, effective, and simple treatment for non-A non-B aortic dissections that can avoid endoleaks, requires no blood products, and has satisfactory early outcomes. (J Thorac Cardiovasc Surg 2022;163:1766-74)

Complete aortic arch replacement with the frozen elephant trunk technique is commonly used to treat entry tears in the aortic arch between the left subclavian artery (LSA) and the left common carotid artery (LCA). ${ }^{1}$ However, the surgical

From the Department of Cardiovascular Surgery, the Second Hospital of Jilin University, Changchun, Jilin, China.

This work was supported by the Basic Department of Jilin Provincial Science and Technology Department, China (Grant No. 20190901008JC), and Bethune Medical Department Doctoral Postgraduate Excellent Talents Training Program Project of Jilin Province, China (Grant No. 20181201).

Institutional Review Board approval: 2018-003.

Received for publication Jan 14, 2020; revisions received May 27, 2020; accepted for publication May 29, 2020; available ahead of print June 22, 2020.

Address for reprints: Kexiang Liu, MD, PhD, 218 Ziqiang St, Changchun, China (E-mail: kxliu64@hotmail.com).

0022-5223

Copyright (C) 2020 The Author(s). Published by Elsevier Inc. on behalf of The American Association for Thoracic Surgery. This is an open access article under the CC BY-NC-ND license (http://creativecommons.org/licenses/by-nc-nd/4.0/).

https://doi.org/10.1016/j.jtcvs.2020.05.100 procedure is complicated and difficult to perform, often leading to unmanageable perioperative and postoperative bleeding. Supra-aortic vessels debranching with thoracic endovascular aortic repair (TEVAR) has been used in place of aortic arch replacement in recent years. ${ }^{2}$ However, common neurologic complications and the patency of a Dacron bypass are primary concerns. ${ }^{3}$ As such, each of these techniques has its own advantages and disadvantages. In our study, we have described a novel and straightforward hybrid technique using a stent-graft (SG) that we modified to treat non-A non-B aortic dissection (AD) without aortic arch

Scanning this QR code will take you to the table of contents to access supplementary information.

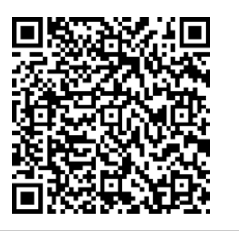




\section{Abbreviations and Acronyms \\ $\mathrm{AD}=$ aortic dissection \\ $\mathrm{CPB}=$ cardiopulmonary bypass \\ $\mathrm{CTA}=$ computed tomography angiography \\ LCA $=$ left common carotid artery \\ LSA = left subclavian artery \\ $\mathrm{SCP}=$ selective cerebral perfusion \\ $\mathrm{SG} \quad=$ stent-graft \\ TEVAR $=$ thoracic endovascular aortic repair}

replacement or debranching. We present consecutive cases of patients from our center.

\section{PATIENTS AND METHODS Study Design}

From January 2013 to December 2018, 825 patients presented with AD. Stanford A ADs accounted for 335 patients (40.6\%), Stanford B ADs accounted for 462 patients $(56 \%$ ), and non-A non-B AD accounted for 28 patients $(3.39 \%)$. Therefore, we conducted a retrospective analysis of 28 consecutive patients with acute non-A non-B AD. The ethics committee at the Second Hospital of Jilin University approved this study. All the 28 patients were informed of the study protocol and gave written informed consent to have their data stored in a database. These patients had an average age of 53.1 years $( \pm 6.25 ; 42-67$ years $)$, and 24 individuals had a history of hypertension (Table 1). All patients reported serious chest or back pain and were admitted to the intensive care unit for medical treatment. The diagnoses were made 6 to 8 hours from symptom onset, and operations were arranged within 24 hours of admission. Among all patients, 3 had preoperative comorbidities of mild aortic valve insufficiency. All entry tears were located at the lesser curvature of the anterior $(1 ; 3.57 \%)$ or posterior $(27 ; 96.43 \%)$ aortic arch between the LCA and the LSA. All 28 patients had their dissection extend distally into the descending aorta.

\section{Materials and Methods}

As previously reported, ${ }^{4}$ The SG Cronus (Microport Medical Co Ltd, Shanghai, China) consists of a self-expandable metallic SG and a Dacron stent-free vascular graft at the proximal end. Our SG (Figure 1, $A$ and $B$ ) was modified to distally add a $10-\mathrm{cm}$ self-expandable nitinol SG, lengthening the proximal Dacron stent-free vascular graft to 25 to $50 \mathrm{~mm}$. The polyester vascular graft had braided polyester sutures and attached outside the stent with a $5-\mathrm{cm}$ free edge at the proximal end (Figure 1,C). The schematic diagram of SG is shown in Figure 1, D.

The SG was available in 4 different sizes (24-30-mm diameters in 2-mm intervals). A preoperative computed tomography angiography (CTA) of the thoracic aorta assessed the extent of the aneurysm and dissection in each case. The diameter of the distal aortic arch and proximal descending aorta was measured by inserting a ball-shaped sizer during operation to determine the appropriate SG size. Typically, the SG shared the same diameter as the distal aortic arch and proximal descending aorta.

The indications were as follows: (1) non-A non-B AD involving the lesser curvature of the aortic arch and anterior or posterior aortic arch and (2) non-A non-B AD spare proximal innominate artery. Contraindication was non-A non-B AD involving the ascending aorta.

\section{Surgical Methods}

This novel hybrid technique was also called the "inclusion aortic arch technique" as described in our previous study. ${ }^{5}$ The hypothermic process
TABLE 1. Demographics

\begin{tabular}{lc}
\hline Surgical cases & 28 \\
Male/female & $18 / 10$ \\
\hline Age & $53.1 \pm 6.25 \mathrm{y}$ \\
History of hypertension & $24(85.7 \%)$ \\
\hline Acute & $28(100.0 \%)$ \\
Persistent chest and back pain & $28(100.0 \%)$ \\
Aortic valve insufficiency & $3(10.7 \%)$ \\
Renal failure & $1(3.57 \%)$ \\
History of stroke & 0 \\
\hline
\end{tabular}

started after general anesthesia through a thermostatic cooling blanket on the patient's back. A standard median longitudinal sternotomy was performed. Cardiopulmonary bypass (CPB) was established via cannulations of the ascending aorta, innominate artery, and the inferior and superior vena cavae. The left side of the heart was vented through the right superior pulmonary vein. Circulatory arrest started at a rectal temperature of $28^{\circ} \mathrm{C}$ to $32^{\circ} \mathrm{C}$, and selective cerebral perfusion (SCP) was performed via the innominate artery.

Transverse incision of the aortic arch wall and bilateral antegrade cerebral perfusion was accomplished after cannulating the LCA. The intimal tear of the dissection was identified (Figure 2, $A$ ) and sealed with mattress sutures of 4-0 Prolene (Figure 2, B). The appropriate SG was then introduced into the descending aorta. After SG released where its proximal edge was just distal to the LSA ostium with double check, we trimmed the vascular graft into an elliptical shape around the LCA and LSA orifices. Then, 1 or 2 pledgetted stitches were placed at the lower margin of LSA orifice with a 4-0 polypropylene double-armed suture needle, which would immobilize the vascular graft and aortic arch tissue.

A single suture stitched the vascular graft to the anterior aortic arch wall from outside to inside the aortic arch and then the reverse direction through all aortic arch wall and vascular graft layers. Another suture was to accomplish the continuous suture by anastomosis of the posterior aortic arch wall and vascular graft as deep as possible. Then, the trimmed vascular graft was attached firmly to the aortic arch wall (Figure 2,C). The transverse incision of the aortic arch wall was closed with 4-0 Prolene sutures. The diagram of this novel hybrid technique is shown in Figure 2, D. Arterial cannulation blood was used for de-airing through the aortic arch incision before the last sutures. Antegrade systemic perfusion was resumed, and the patient was rewarmed. Hemostasis and incision closure were performed per standard procedure, and the patient was transferred to the intensive care unit.

\section{Statistics}

Continuous data were expressed as a mean \pm standard deviation, and categoric variables were expressed as percentages. The Fisher exact test and chi-square test were used to compare categoric variables. The cumulative survival curve for long-term follow-up was constructed using the Kaplan-Meier method. All statistical analyses were performed with SPSS 20.0 software (SPSS Inc, Chicago, Ill)

\section{RESULTS}

No patients died during surgery. All entry tears were located at the lesser curvature (Figure 3,A). The mean time of circulatory arrest time was $24.8 \pm 2.98$ minutes and that of aortic crossclamp was $29.3 \pm 3.14$ minutes. 


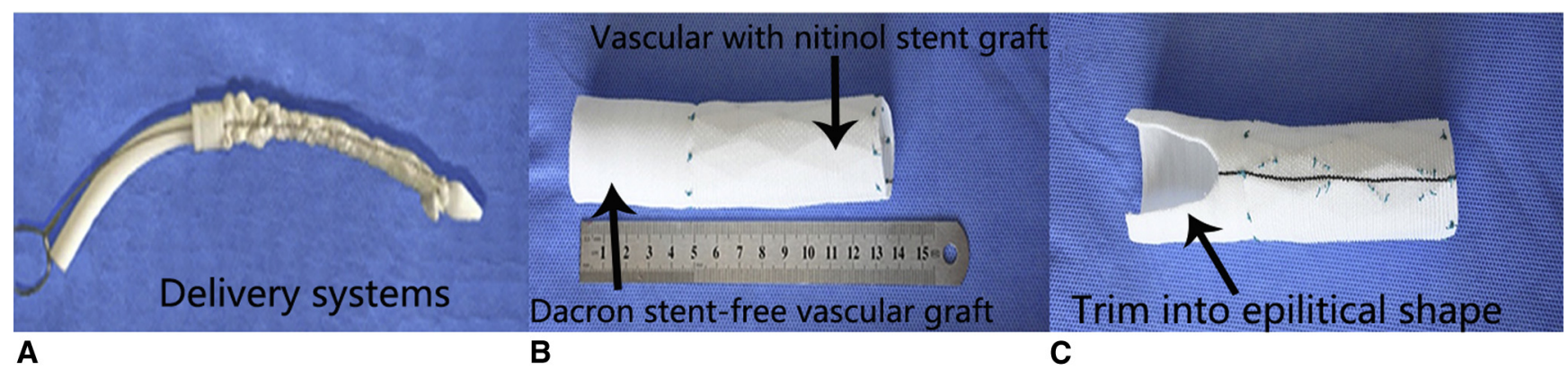

\section{A}

\section{B}

\section{C}

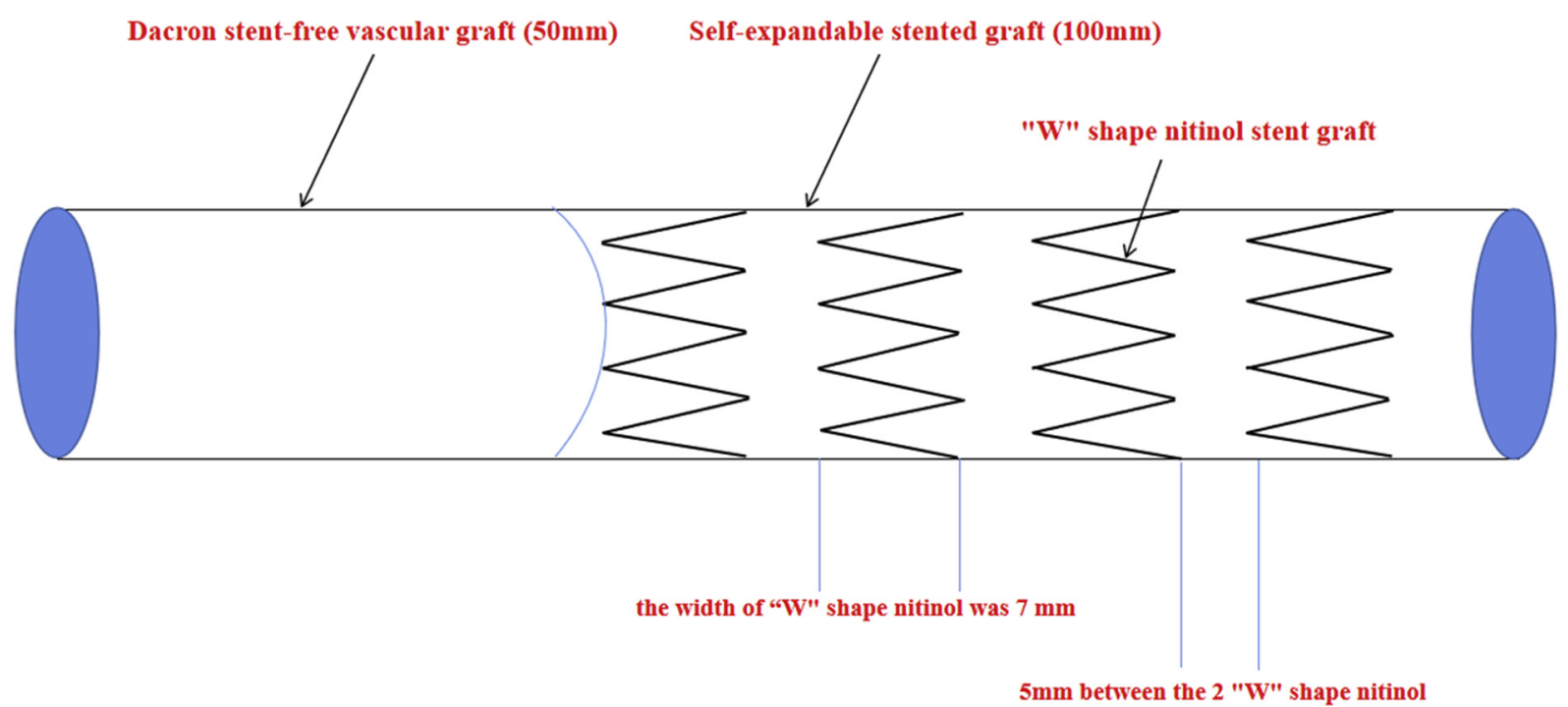

FIGURE 1. Self-modified SG. A, Compacted modified SG with the delivery system before implantation. B, SG in the expanded state: a distal 10-cm selfexpandable nitinol SG and the proximal 50-mm Dacron stent-free vascular graft. C, Example of the trimmed vascular graft used for the aortic arch inclusion technique. Trim the vascular graft into an elliptical shape around the LSA and LCA orifices. D, Schematic diagram of the novel SG. Our modified SG contains the proximal 50-mm Dacron stent-free vascular graft and a distal 10-cm self-expandable nitinol SG. Self-expandable nitinol SG consisted of a "W" shaped nitinol SG. The width of the "W" shaped nitinol is $7 \mathrm{~mm}$. The distance between the 2 "W" shaped nitinol is $5 \mathrm{~mm}$.

The length of $\mathrm{CPB}$ and operation were $78.3 \pm 5.33$ minutes and $255.7 \pm 24.3$ minutes, respectively (Table 2 ). All of the patients were discharged without complications. No blood transfusion occurred among any patients. There were no early adverse events, such as paraplegia, cerebral infarction, upper limb ischemia, or endoleaks. There were also no reoperations (Table 3). All of the patients underwent CTA examination before discharge. One patient presented with partial aortic arch and false lumen patency in the descending aorta.

CTA was conducted at 6 months $(\mathrm{n}=9)$ and 1 year $(\mathrm{n}=6), 2(\mathrm{n}=7), 3$ years $(\mathrm{n}=4)$, and greater than 3 years $(\mathrm{n}=2)$ for follow-up (Figure 3,B). The median follow-up time from surgery to final CTA imaging was $15.32 \pm 9.21$ months. For patients who had a 6-month CTA follow-up, the diameter of the distal aortic arch was significantly smaller $(31.94 \pm 6.95 \mathrm{~mm})$ than the preoperative condition $(36.76 \pm 4.15 \mathrm{~mm})(P=.0027)$. The diameter of the descending aorta was smaller $(34.84 \pm 4.15 \mathrm{~mm})$ than the value preoperatively measured $(37.3 \pm 4.7 \mathrm{~mm})(P=.0419)$ (Figure $3, C$ and $D$; Table 4). Aortic arch and descending aorta false lumen partial patency persistence were found in 1 patient. This patient had CTA 10 days after the operation, and the diameters of the distal aortic arch and the descending aorta were 33.6 and $34.8 \mathrm{~mm}$, respectively. This patient's 6-month CTA showed the diameter of the aortic arch as $32.7 \mathrm{~mm}$ and of the descending aorta as $32.1 \mathrm{~mm}$, showing no signs of enlargement. We continued to monitor this patient carefully.

Median follow-up time was $39.12 \pm 15.04$ months (6.074.0 months) (Table 5). One patient was lost to follow-up, and 1 patient died within the follow-up period. 

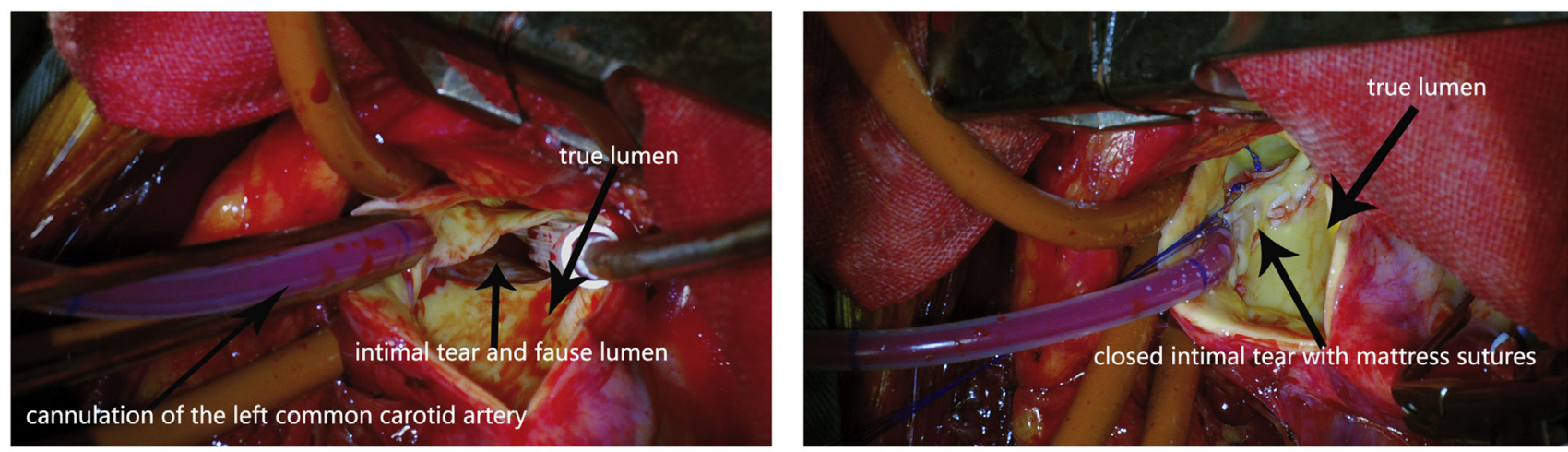

A

$\mathbf{B}$
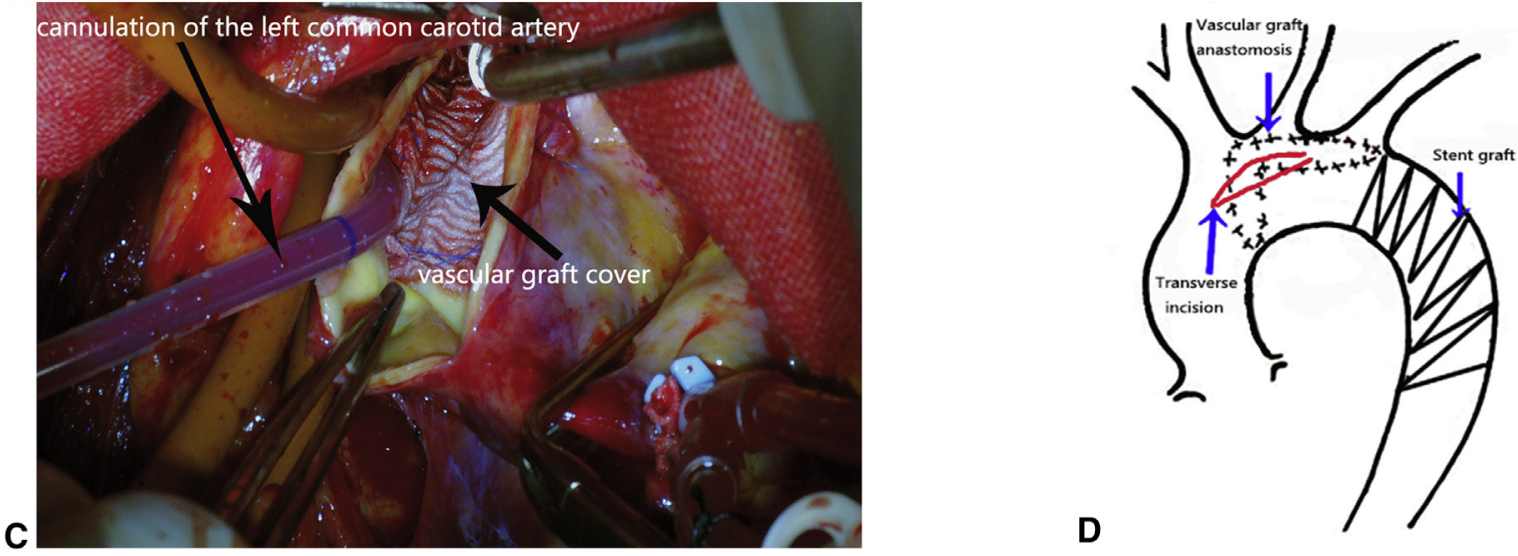

FIGURE 2. Intraoperative photograph during the aortic arch inclusion technique. A, The intimal tear was easily found under direct vision, and the false and true lumen were identified. B, Tightly suture the intimal tear with mattress sutures of 4-0 Prolene. C, The greater curvature of the vascular graft was cut longitudinally to expose the orifices of 3 vessels thoroughly. Suture the vascular graft to the anterior and posterior aortic arch wall. D, The stent part of the SG was implanted anterogradely into the true lumen of descending aorta. The proximal end of the stent was deployed distal to the origin of the LSA. The vascular graft free of the stent was located inside the natural arch for the inclusion that was to follow.

The Kaplan-Meier curve of survival is shown in Figure 4. No events such as retrograde, paraplegia, cerebral infarction, upper limb ischemia, or LSA ischemia were reported.

\section{DISCUSSION}

Stanford and Debakey classifications have been used for approximately 5 decades in clinical practice. However, AD involving the aortic arch while sparing the ascending aorta is not addressed in these 2 classifications. Pasic and colleagues ${ }^{6}$ defined a term for non-A non-B dissections in which an intimal tear was localized in the aortic arch in 1999, but this unique case of non-A non-B AD rarely occurs. As such, the best therapeutic option for such patients remains controversial. In this study, we reported 28 patients with non-A non-B dissections who were effectively treated with our novel inclusion aortic arch surgical management in acute periods (Figure 5).

Traditional treatment of non-A non-B dissections includes basic medical treatment and emergency aortic arch replacement. As Urbanski and Wagner reported, ${ }^{7} 3(75 \%)$ of 4 patients treated conservatively died at 1,3 , and 28 months after the onset of dissection. In the modern era, basic medical treatment has been replaced by surgical management, including aortic arch replacement and frozen elephant trunk in the descending aorta. These procedures seem to offer improved clinical outcomes and long-term survival. ${ }^{8}$ Nevertheless, these surgical methods are complex with the opportunity of unmanageable bleeding, which is the cause of mortality. ${ }^{9}$ Therefore, a simplified surgical procedure is necessary for non-A non-B dissection treatment. Compared with aortic arch replacement, all the anastomoses in the inclusion aortic arch technique were within the aortic arch; this prevented anastomoses from bleeding, especially those at the distal or posterior sites. Also, aortic arch replacement and brachiocephalic vessels do not need to be replaced.

The traditional hybrid technique, combined with the debranching technique, is an elaborate surgical procedure comparable to a standard arch replacement. Nevertheless, reports have shown that endoleaks represent one of the 


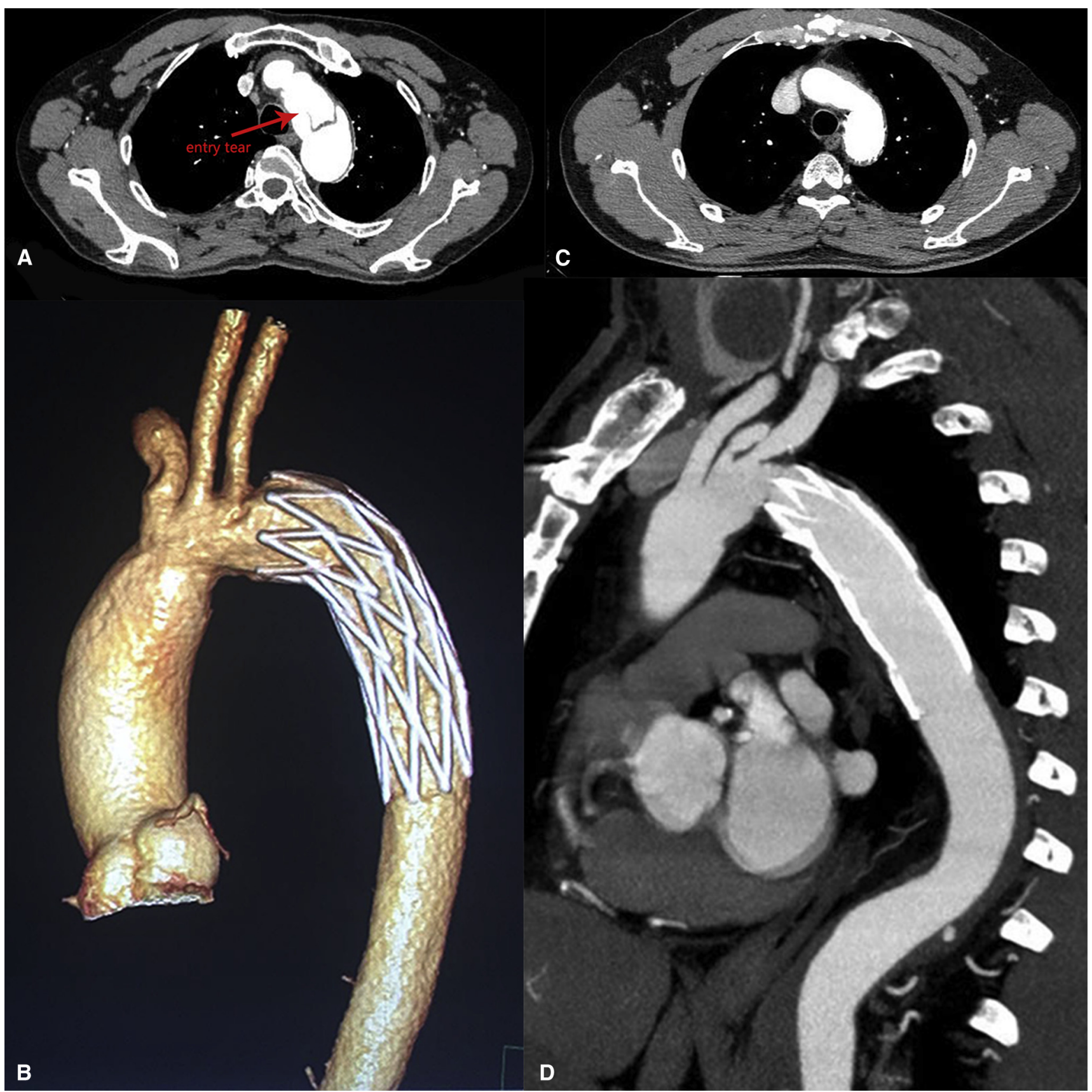

FIGURE 3. Postoperative photograph. A, Intimal tear in the aortic arch before the operation. B, Postoperative re-exam CTA at 6 months. Threedimensional CTA after implantation of a modified hybrid graft in a patient with acute non-A non-B AD. C and D, CTA of a patient with acute non-A non-B AD after implantation of a modified hybrid graft 6 months postoperatively. Perigraft space around the stented segment of the hybrid prosthesis in the aortic arch and descending aorta is thrombosed.

major causes of failure. ${ }^{10,11}$ Several authors have emphasized that type I endoleaks after TEVAR should be treated aggressively, ${ }^{11}$ which is dangerous and complicated. Rylskia and colleagues ${ }^{8}$ reported that traditional hybrid techniques yielded satisfactory results with a 1-year survival of $90 \%$, and up to $33 \%$ of patients required secondary aortic interventions. With the inclusion aortic arch technique, intima entry could be sealed with 4-0 polypropylene and followed by a vascular graft covering the primary tear, which is effective in avoiding endoleaks and promotes aortic arch false lumen closure. In our study, all patients presented with an intimal tear localized in the aortic arch that 
TABLE 2. Intraoperative parameters

\begin{tabular}{lc}
\hline Cases & 28 \\
\hline Aortic crossclamp time & $29.3 \pm 3.14 \mathrm{~min}$ \\
Circulatory arrest time & $25.8 \pm 2.98 \mathrm{~min}$ \\
CPB time & $78.3 \pm 5.33 \mathrm{~min}$ \\
Length of operation & $255.7 \pm 24.3 \mathrm{~min}$ \\
Temperature of circulatory arrest & $29.6^{\circ} \mathrm{C} \pm 0.31^{\circ} \mathrm{C}$ \\
\hline
\end{tabular}

$C P B$, Cardiopulmonary bypass.

was closed during the operation. During the average time of follow-up, there were no complications. Aortic arch false lumen patency persisted in 1 patient before discharge, but there was no progression during the follow-up period.

As the main component of traditional hybrid technique, TEVAR was limited in the acute phase because of retrograde type A AD (4.3\%-8.4\%). This retrograde is a catastrophic complication of TEVAR and total debranching, which causes fatal aortic rupture, ${ }^{12}$ with a 30 -day mortality rate of up to $57 \% .^{13}$ In contrast, the inclusion aortic arch technique is safer than TEVAR in the acute phase, and all 28 patients survived without retrograde dissection because the intima entry was credibly sealed by mattress suturing and followed with vascular graft covering. The stent-free Dacron vascular was sutured to normal aortic arch tissues. Also, inserting the SG into the descending aorta could close the false lumen. Our modified SG did not contain a bare metal stent, which was different from the SG in TEVAR. Another complication during debranching was stroke. Risks of LSA revascularization will induce stroke and potentially damage the associated subclavian artery and vein, brachial plexus, vagus nerve, and phrenic nerve. ${ }^{14,15}$ Midterm survival of debranching bypass after TEVAR is only $50 \% \pm 11.1 \%$. ${ }^{16}$ Late patency of the debranching graft for revascularization is also a serious concern when using

TABLE 3. Postoperative parameters

\begin{tabular}{lc}
\hline Cases & 28 \\
Consciousness recovery time & $13.7 \pm 3.15 \mathrm{~h}$ \\
\hline Ventilation time & $21.3 \pm 3.19 \mathrm{~h}$ \\
\hline First 24-h drainage & $179.2 \pm 35.1 \mathrm{~mL}$ \\
\hline ICU time & $61.3 \pm 12.2 \mathrm{~h}$ \\
\hline Hospital time & $9.2 \pm 1.69 \mathrm{~d}$ \\
\hline Thoracic reexploration & 0 \\
\hline Paraplegia & 0 \\
\hline Aortic arch false lumen patency & $1(3.57 \%)$ \\
SG-related complication & 0 \\
\hline New cerebral complication & 0 \\
Renal failure requiring dialysis & 0 \\
\hline
\end{tabular}

$I C U$, Intensive care unit; $S G$, stent-graft.
TABLE 4. Data on remodeling of the thoracic aorta

\begin{tabular}{lccc}
\hline & $\begin{array}{c}\text { Preoperatively } \\
\text { CTA }(\mathbf{m m})\end{array}$ & $\begin{array}{c}\text { At discharge } \\
\text { CTA }(\mathbf{m m})\end{array}$ & $\boldsymbol{P}$ value \\
\hline Distal aortic arch & $36.76 \pm 4.15$ & $31.94 \pm 6.95$ & .0027 \\
Descending aortic & $37.31 \pm 4.7$ & $34.84 \pm 4.15$ & .0419 \\
\hline
\end{tabular}

CTA, Computed tomography angiography.

this technique. Therefore, our novel inclusion aortic arch technique had great advantages in avoiding neurologic complications and long-term survival compared with debranching, with far less concern for acute complications and late patency of the debranching graft.

In this study, our hybrid technique was effective for nonA non-B AD. Although there were no cases with an entry tear located between the LCA and the LSA of the great curvature among the 28 patients, we encountered this predicament within a Stanford A AD. If possible, we sealed the entry tear, ligated the LSA, and performed the ascending aorta artery-LSA bypass. ${ }^{5}$ On the basis of our available results, we inferred that if the entry tear was located in the great curvature in a non-A non-B AD, this method would also be effective.

The hemiarch procedure might be an alternative for nonA non-B AD treatment; however, the complexity was greater than in our hybrid method. Therefore, we did not use this method to treat patients with non-A non-B AD. Notably, simply sealing the primary entry tear possibly invites surgical failure if further reinforcement is not applied. In our study, the intima entry was sealed by suturing and followed by a vascular graft covering. Then, the SG was placed into the descending aortic artery, the false lumen was closed, and the pressure was eliminated.

Since 2008, the inclusion aortic arch technique has been used to treat Stanford A AD. Six months postoperatively, the known rates of aortic arch false lumen closure and

TABLE 5. Early and midterm follow-up

\begin{tabular}{lcc}
\hline & $\begin{array}{c}\text { CTA (6-mo } \\
\text { follow up) }\end{array}$ & $\begin{array}{c}\text { CTA (latest } \\
\text { follow-up) }\end{array}$ \\
\hline Cases & 28 & $27(96.43 \%)$ \\
Death & 0 & $1(3.70 \%)$ \\
\hline Paraplegia & 0 & 0 \\
\hline Aortic arch false lumen Patency persisted & $1(3.57 \%)$ & $1(3.70 \%)$ \\
\hline SG-related complication & 0 & 0 \\
New cerebral complication & 0 & 0 \\
Renal failure requiring dialysis & 0 & 0 \\
Patient loss to follow-up & 0 & $1(3.70 \%)$ \\
\hline Reintervention & 0 & 0 \\
\hline CTA, Conp & &
\end{tabular}

CTA, Computed tomography angiography; $S G$, stent-graft. 


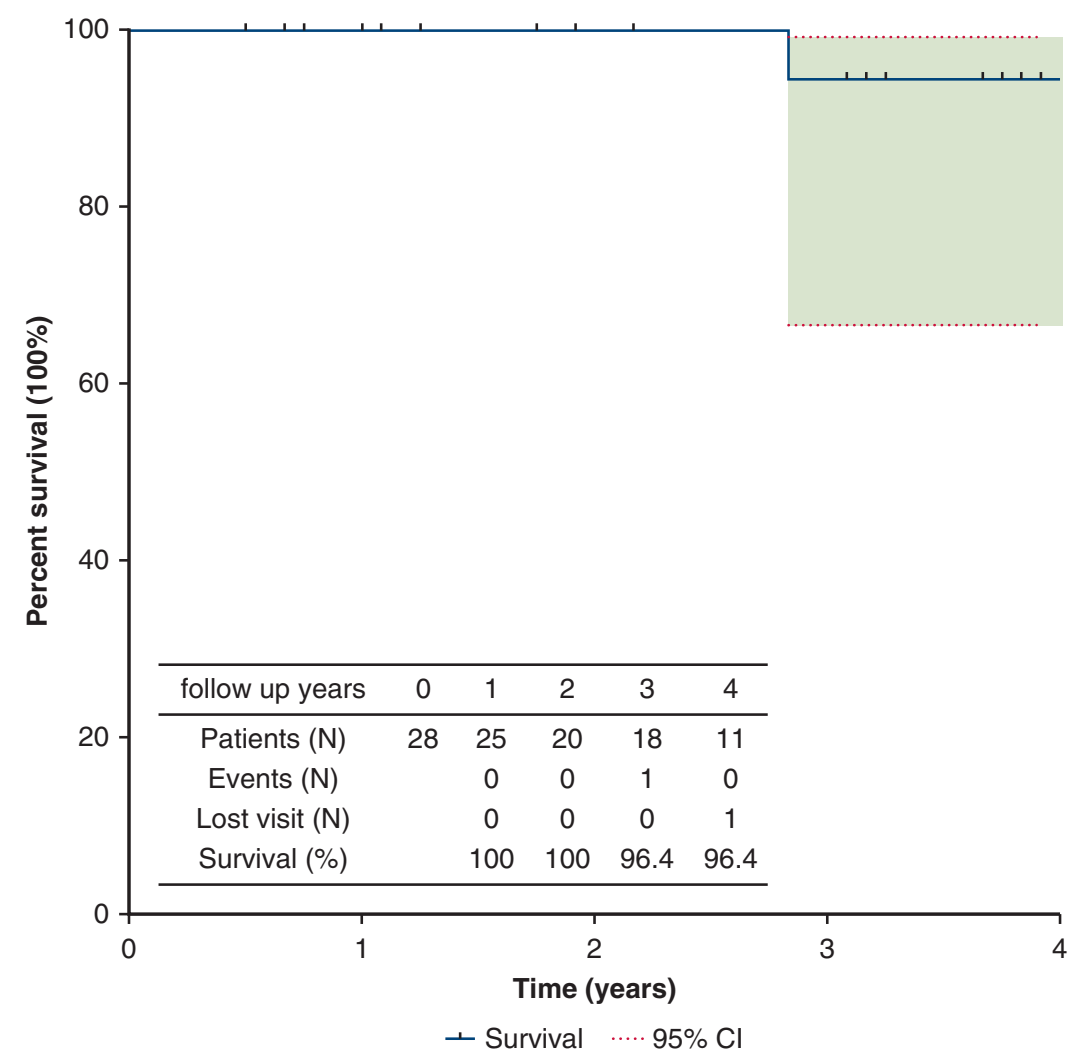

FIGURE 4. Kaplan-Meier curve estimates in the populations. One patient died at 34 months, and 1 patient was lost to follow-up at 39 months after surgery. The predicted survival was $100 \%, 100 \%, 96.4$, and $96.4 \%$ at $1,2,3$, and 4 years, respectively. $C I$, Confidence interval.

descending thoracic aorta false lumen thrombosis are $92.4 \%$ and $74.3 \%$, respectively. ${ }^{5}$ On the basis of the experiences of the inclusion aortic arch technique for treating Stanford A AD, we applied this technique to treat acute non-A non-B AD. This technique also could be used to treat aortic arch aneurysms. We firmly attached the trimmed vascular graft to the aortic arch wall to isolate the aortic arch aneurysm. Although its application has benefited a number of patients with arch aneurysm, more samples are necessary to investigate its effectiveness, which is one of our undergoing tasks.

This modified SG shares a similar structure to that of the E-vita graft (Jotec, Hechingen, Germany), which is widely used to treat Stanford A AD ${ }^{17}$ The difference is the length of the distal self-expandable nitinol SG $(100 \mathrm{~mm})$, because our SG is shorter than the E-vita graft $(150 \mathrm{~mm})$. Although the E-vita graft was not yet available in China, the structure of our SG was similar to that of the E-vita graft; therefore, we believed that the E-vita graft was compatible for our novel inclusion aortic arch technique.

Our novel aortic arch inclusion technique is simple to perform and has satisfactory early outcomes. During the operation, we could visualize the true lumen after transversely incising the aortic arch; therefore, we introduced the SG to the true lumen without a guidewire. However, it is questionable if the superiority regarding to efficacy justifies the invasiveness and risks from deep hypothermic circulatory arrest and CPB. In our technique, the moderate hypothermic technique combined with SCP and spinal cord protection was used. Moderate hypothermic circulatory arrest time was less than 25 minutes, and CPB time was approximately 78 minutes with our method, which is recognized as a safe approach, as we previously described. ${ }^{4}$ No complications occurred after the operation, and during follow-up, there were no reports of moderate hypothermic circulatory arrest or $\mathrm{CPB}$ in any patients. A systemic temperature of $28^{\circ} \mathrm{C}$ has been used in our center since 2014 for treating type A AD, because cooling the back after induction of general anesthesia at $28^{\circ} \mathrm{C}$ could sufficiently protect the spinal cord as previously reported. ${ }^{5}$

This novel technique made the upper ministernotomy approach possible. ${ }^{18}$ Since 2018, 3 patients with non-A non-B ADs were reported to benefit from this 


\section{Non $\mathrm{A}$ and non $\mathrm{B}$ aortic dissection}

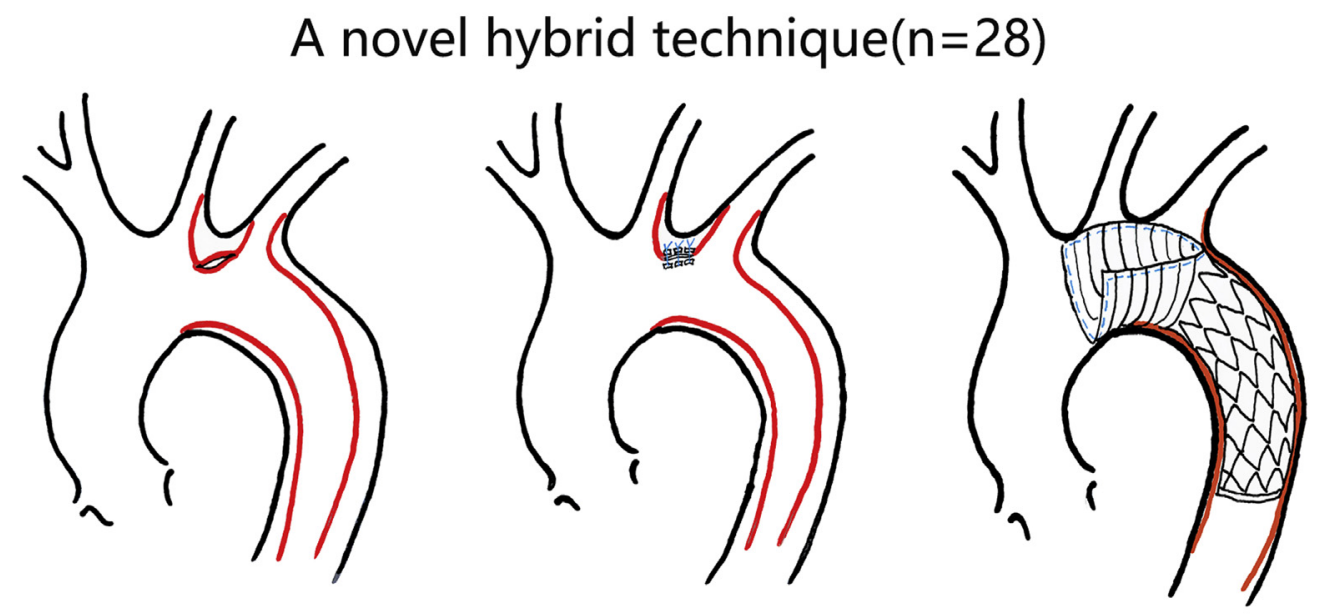

Data on remodeling of the thoracic aorta.

\begin{tabular}{lccc}
\hline & $\begin{array}{c}\text { Preoperatively } \\
\text { CTA }(\mathrm{mm})\end{array}$ & $\begin{array}{c}\text { At discharge } \\
\text { CTA }(\mathrm{mm})\end{array}$ & P value \\
\hline Distal aortic arch & $36.76 \pm 4.15$ & $31.94 \pm 6.95$ & 0.0027 \\
Descending aortic & $37.3 \pm 4.7$ & $34.84 \pm 4.15$ & 0.0419 \\
\hline
\end{tabular}

Results: No endoleaks. Require no blood products. Complete aortic arch false lumen closure rate and descending aortic false lumen close rate is $96.43 \%$, respectively.

Implications: Our hybrid technique is a safe, effective, and simple treatment for non-A non-B aortic dissections.

FIGURE 5. Adoption of the hybrid technique for patients with non-A non-B AD. Schematic diagram of the novel hybrid technique. Adoption of our hybrid technique for 28 patients with non-A non-B AD. The intimal tear was first found under direct vision. Tightly suture the intimal tear with mattress sutures of 4-0 Prolene. The SG was implanted anterogradely into the true lumen of descending aorta. The proximal end of the stent was deployed distal to the origin of the LSA. The vascular graft free of the stent was located inside the natural arch for the inclusion that was to follow. The greater curvature of the vascular graft was cut longitudinally to expose the orifices of 3 vessels thoroughly. Suture the vascular graft to the anterior and posterior aortic arch wall. No blood products were used in any patient. There were no early events, including endoleaks and retrograde. Complete aortic arch false lumen closure and descending aortic false lumen close rates were $96.43 \%$. Our hybrid surgical method provides a new treatment for non-A non-B ADs. It is a safe, effective, and simple treatment that can avoid endoleaks and retrograde, and requires no blood products with satisfactory early outcomes. CTA, Computed tomography angiography.

ministernotomy technique, and the blood loss was significantly less than the conventional sternotomy (Video 1).

\section{Study Limitations}

First, this was a retrospective observational study at a single center, which might influence the generalizability of the results. Limitation in sample size and selection bias exists in our study to some degree; therefore, a final determination requires a prospective, multicenter study with larger sample sizes. In addition, more long-term follow-up periods would be preferred in the future.

\section{CONCLUSIONS}

The inclusion aortic arch technique is a safe, effective, and simple treatment for non-A non-B ADs and can avoid endoleaks. Our initial outcomes were excellent, and more studies are warranted to fully establish the long-term safety and efficacy of our new procedure.

\section{Conflict of Interest Statement}

The authors reported no conflicts of interest.

The Journal policy requires editors and reviewers to disclose conflicts of interest and to decline handling or 


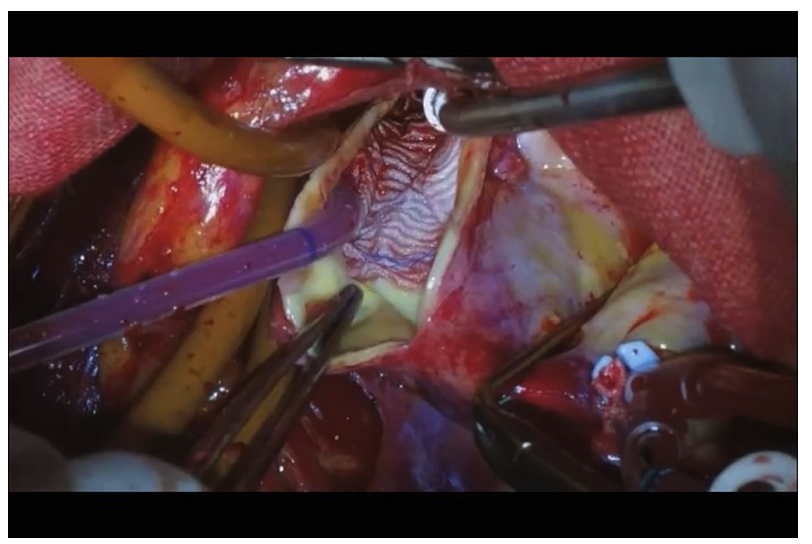

VIDEO 1. The steps of the technique combined with ministernotomy approach are presented in a patient with acute non-A non-B AD. This hybrid technique was also called the "inclusion aortic arch technique," as our previous study described. ${ }^{5}$ After cannulation of the innominate artery, superior vena cava, femoral artery, and vein, circulatory arrest was started at a rectal temperature of $282^{\circ} \mathrm{C}$ to $32^{\circ} \mathrm{C}$, and SCP was performed via the innominate artery. Transverse incision of the aortic arch wall and bilateral antegrade cerebral perfusion was accomplished after cannulation of the LCA. The intimal tear of the dissection was identified and closed with mattress sutures of 4-0 Prolene. The appropriate SG was introduced into the descending aortic artery. After releasing the SG and ensuring that the proximal side of SG was just distal to LSA ostium, the vascular graft is trimmed into a epilitical shape around the LCA and LSA orifice. Then, 1 or 2 pledgetted stitches were placed at the lower margin of LSA orifice, which would immobilize vascular graft and aortic arch tissue. One needle was picked to suture the vascular graft to the posterior aortic arch wall as deeply as possible. Another needle was picked to suture the vascular graft to the anterior aortic arch wall from the outside of the aortic arch to the inside of the aortic arch, and then from inside to outside through all layers of the aortic arch wall and vascular graft. The transverse incision of the aortic arch wall was closed with sutures of 4-0 Prolene. Blood from arterial cannulation was used to de-air through the incision of the aortic arch before the last sutures. Video available at: https://www.jtcvs.org/article/S00225223(20)31530-0/fulltext.

reviewing manuscripts for which they may have a conflict of interest. The editors and reviewers of this article have no conflicts of interest.

\section{References}

1. Tian DH, Wan B, Di Eusanio M, Black D, Yan TD. A systematic review and meta-analysis on the safety and efficacy of the frozen elephant trunk technique in aortic arch surgery. Ann Cardiothorac Surg. 2013;2:581-91.
2. Neequaye S, Abraham CZ. Total endograft replacement of aortic arch. Ann Cardiothorac Surg. 2013;2:362-6.

3. de Oliveira Souza L, de Castro Bernardes R, Navarro TP, Procópio RJ, Filho FARR, Lima LCM, et al. Hybrid Treatment with complete transposition of supra-aortic trunks versus conventional surgery for the treatment of aortic arch aneurysm. Braz J Cardiovasc Surg. 2017;32:354-60.

4. Wang W, Piao H, Wang Y, Li B, Wang T, Xu R, et al. Long-term outcomes of hybrid technique of complicated type B aortic dissection. Ann Thorac Surg. 2019; 107:1319-25.

5. Liu K, Zhu C, Zheng X, Wang T, Xu R, Zhu Z, et al. A new aortic arch inclusion technique with frozen elephant trunk for type A aortic dissection. Ann Surg. 2020;271:978-83.

6. Pasic M, Knollman F, Hetzer R. Isolated non-A-non-B dissection of the aortic arch. N Engl J Med. 1999;341:1775.

7. Urbanski PP, Wagner M. Acute non-A-non-B aortic dissection: surgical or conservative approach? Eur J Cardiothorac Surg. 2016;49:1249-54.

8. Rylskia B, Pe'reza M, Friedhelm Beyersdorfa F, Reser D, Kari FA, Siepe M, et al. Acute non-A non-B aortic dissection: incidence, treatment and outcome. Eur J Cardiothorac Surg. 2017;52:1111-7.

9. Dohle DS, Tsagakis K, Janosi RA, Franke UFW, Pacini D, Di Bartolomeo R, et al. Aortic remodelling in aortic dissection after frozen elephant trunk. Eur J Cardiothorac Surg. 2016;49:111-7.

10. Preventza O, Wheatley GH, Ramaiah VG, Rodriguez-Lopez JA, Williams J, Olsen D, et al. Management of endoleaks associated with endovascular treatment of descending thoracic aortic diseases. J Vasc Surg. 2008;48:69-73.

11. Parmer SS, Carpenter JP, Stavropoulos SW, Cury M, Hernandez AV, Mohabbat W, et al. Endoleaks after endovascular repair of thoracic aortic aneurysms. J Vasc Surg. 2006;44:447-52.

12. Peterson BG, Eskandari MK, Gleason TG, Morasch MD. Utility of left subclavian artery revascularization in association with endoluminal repair of acute and chronic thoracic aortic pathology. J Vasc Surg. 2006;43:433-9.

13. Kpodonu J, Preventza O, Ramaiah VG, Shennib H, Wheatley GH III, RodriquezLopez J, et al. Retrograde type A dissection after endovascular stenting of the descending thoracic aorta. Is the risk real? Eur J Cardiothorac Surg. 2008;33: 1014-8.

14. Rizvi AZ, Murad MH, Fairman RM, Erwin PJ, Montori VM. The effect of left subclavian artery coverage on morbidity and mortality in patients undergoing endovascular thoracic aortic interventions: a systematic review and meta-analysis. J Vasc Surg. 2009;50:1159-69.

15. Cooper DG, Walsh SR, Sadat U, Noorani A, Hayes PD, Boyle JR. Neurological complications after left subclavian artery coverage during thoracic endovascular aortic repair a systematic review and meta-analysis. J Vasc Surg. 2009;49: 1594-601.

16. Benedetto F, Piffaretti G, Tozzi M, Pipito’ N, Spinelli D, Mariscalco G. Midterm outcomes of carotid-to-carotid bypass for hybrid treatment of aortic arch disease. Ann Vasc Surg. 2014;28:860-5.

17. Verhoye JP, Anselmi A, Kaladji A, Flécher E, Lucas A, Heautot J-F, et al. Mid-term results of elective repair of extensive thoracic aortic pathology by the Evita Open Plus hybrid endoprosthesis only. Eur J Cardiothorac Surg. 2014;45:812-7.

18. Huang M, Piao H, Li B, Wang Y, Wang T, Zhu Z, et al. A new inclusion technique through an upper partial sternotomy for complicated Stanford B-type aortic dissection with an aberrant right subclavian artery: a case report. Medicine (Baltimore). 2019;98:e14727.

Key Words: non-A non-B aortic dissection, hybrid treatment, inclusion aortic arch technique 